\title{
Hedge Funds, Arbitrage, and Timing
}

\author{
Daniel T. Lawson ${ }^{1}$, Robert L. Schwartz ${ }^{2} \&$ Seth D. Thomas ${ }^{1,3}$ \\ ${ }^{1}$ Indiana University of Pennsylvania, Department of Finance \& Legal Studies, Indiana, PA 15705, USA \\ ${ }^{2}$ First Commonwealth Advisors, Investment Management \& Trust Department, Pittsburgh, PA 15219, USA \\ ${ }^{3}$ Alcentra, U.S. Direct Lending, New York, NY 10166, USA \\ Correspondence: Daniel T. Lawson, Indiana University of Pennsylvania, Department of Finance \& Legal Studies, \\ Indiana, PA 15705, USA. Tel: 1-724-357-9774. E-mail: dlawson@iup.edu
}

Received: November 7, 2020

Accepted: December 2, $2020 \quad$ Online Published: December 10, 2020

doi:10.5539/ijef.v13n1p45

URL: https://doi.org/10.5539/ijef.v13n1p45

\begin{abstract}
This paper is an extension of the work of Lawson and Schwartz (2018) which analyzes the risk-adjusted performance of hedge funds by employing a collection of four, five, seven, and eight-factor models. The purpose is to evaluate how well the top and bottom performing subset of hedge fund strategies have profited on known asset pricing anomalies during two unique time periods, 1994 to 2000 and 2001 to 2008. The bifurcation of the data into two distinct periods allows for a deeper exploration of the potential time-varying significance of estimated factor arbitrage. Our empirical testing suggests that both the top and bottom performing funds did utilize the asset growth anomaly to generate abnormal profits. Top performers tended to invest with a long emphasis on low asset growth, value firms while the bottom-five performing hedge fund strategies tested positive for a predilection towards going long small firms with low asset growth characteristics. Arguably, these outcomes probably align with the nature of the investment philosophy of each fund strategy. Interestingly, however, the time-varying significance of estimated coefficients for the value and returns momentum factors between the two distinct timeframes suggests either intentional or unintentional rotation between the use of available pricing anomalies and risk premiums.
\end{abstract}

Keywords: hedge funds, arbitrage, market anomalies, behavioral finance, efficient markets

\section{Introduction}

\subsection{Hedge Funds}

Hedge funds are alternative investment vehicles set up as private investment partnerships which employ intricate strategies oftentimes involving both long and short positions, financial derivatives, and considerable leverage targeting several asset classes and geographic markets. They do so in an effort to generate substantial absolute returns for accredited investors. Such investors include high net-worth individuals and institutional clientele who are characterized by a high degree of risk tolerance. Further, hedge funds are purported to be run by sophisticated investment professionals with access to a wide array of data, information systems, and other resources. These characteristics support the theoretical notion that hedge fund managers are well-equipped to arbitrage on known market anomalies if such an opportunity does indeed exist.

\subsection{Bifurcation of Time Period}

Two distinct seven-year time periods are analyzed in this paper, 1994 to 2000 and 2001 to 2008 . Both time periods include bull and bear market cycles and are bifurcated accordingly for two main reasons. First, it is well known that despite having a stated strategy, hedge funds tend to be opportunistic and employ dynamic strategies. Excessive or moderate changes in strategy over time may mask the loading on the anomaly factors, especially if subsequent strategies are opposite to each other, e.g., employing a short-equity strategy after a long-equity strategy. Secondly, using these two time periods allows us to test the persistence of the subject anomalies. If heavy loading on an anomaly factor is observed in the first time period but not the second, it may support the notion that markets are highly efficient. In contrast, if heavy loading is observed in both time periods it may suggest inefficiency.

\subsection{Investment Practices}

On the basis that hedge fund managers obtain the skill, resources, and legal latitude to pursue complex 
investment strategies, we can group them into a set of common core classifications. The Barclay Hedge Fund DataFeeder assigns performance reporting hedge funds into eighteen distinct strategy cohorts. In their infancy, hedge funds often begin by running a single, flagship strategy but subsequently adopt a combination of strategies across the investment partnership. We assume hedge funds in our sample run a singular strategy unless they self-report otherwise. Grouping funds into strategy-specific portfolios, we test our sample's ability to make use of published asset pricing anomalies which have been documented as statistically significant extensions of traditional asset pricing models. If they are skillful enough to do so, substantial abnormal profits may result, ultimately justifying their value proposition.

\section{Literature Review}

\subsection{The Lineage of Asset Pricing Models}

Since the 1960s, a substantial body of research has amassed pertaining to the mathematical quantification of the determinants of capital asset prices and their resulting periodic returns. Certainly, the most notable model is that which grew out of Treynor (1961 and 1962), Sharpe (1964), Lintner (1965a, b), and Mossin (1966). This traditional model is dubbed the Capital Asset Pricing Model ("CAPM") and was inspired by Harry Markowitz's popularly titled, "Modern Portfolio Theory". The CAPM posits a market equilibrium theory detailing the nature of asset prices under conditions of risk. Through this mean-variance equilibrium model, the expected return on capital assets is a function of the risk of the asset, such that the return premium is proportional to the market beta. Derivative versions of the CAPM were later developed, such as the Merton (1973), Breeden (1979), Reinganum (1981), and Breeden, Gibbons, and Litzenberger (1989) Intertemporal Capital Asset Pricing Models ("ICAPM") which address the issue of time-varying investment opportunity sets and dynamic utility functions faced by rational investors. As in Lawson and Schwartz (2018), we take the traditional CAPM as a starting point to build our empirical model.

In Ross (1976), Arbitrage Pricing Theory was introduced which postulated that under a no arbitrage assumption, expected returns on capital assets should be linearly related to the covariance in certain explanatory factors. This was a motivating work in the early stages of multi-factor asset pricing models. One of the most distinguished models of this genre is that of Fama and French (1993) which proposed that the expected return on a common stock should be adequately explained by market, value, and size risk premiums which compensate for variation in stock-specific economic fundamentals. Carhart (1997) extended this model to include a twelve-month stock return momentum factor which appeared to be a pricing anomaly in Jegadeesh and Titman (1993). Later works by Cooper, Gulen, and Schill (2007), Chordia and Shivakumar (2006), and Hershleifer and Jiang (2007) found several additional pricing anomalies related to asset growth, earnings momentum, and equity financing activity, respectively.

Our research takes the form of the Fama and French (1993) linear multi-factor model, incorporates the pricing anomaly factors identified in the various aforementioned studies, and tests the average hedge fund managers' ability to generate abnormal excess returns by using the supposed market mispricing's. One potential issue must be addressed, however.

As highlighted by Fung and Hsieh (2001) and Mitchell and Pulvino (2001), due to the nature of hedge fund investments which can involve the use of financial leverage, derivatives, and evolving trading strategies, the risk-return patterns of these funds can exhibit nonlinearity. Left untended to, this could prove to be a troublesome misspecification of our linear models since such models have a heightened sensitivity to nonlinear relationships between dependent and independent variables. Fortunately, nonlinear, asymmetric hedge fund returns oftentimes characterized by significant left tail risk - can be controlled for by adding nonlinear functions of explanatory variables as regressors. To that end, we choose to integrate the Fung and Hsieh (2001) bond, currency, commodity, short-term interest rate, and stock index lookback straddle factors since the payoffs of straddle options behave similarly to hedge fund returns.

Lastly, as mentioned, we allow our multifactor models to take a form which is supported by existing literature, however, these models do not align with the another similar body of work involving active manager performance attribution. Such alternative works employ multifactor models which include regressors measuring the ex-post returns of asset class indices, both international and domestic. See Sharpe (1992) and Fung and Hsieh (2001) for an example applied to the mutual fund and hedge funds universes, respectively. Considering hedge funds have been shown to have little correlation with standard asset indices we made the determination to explore a fundamentals-driven model that expands upon the traditional Fama and French (1993) and Carhart (1997) factors. Nonetheless, our models could still be interpreted for performance attribution with the factor loadings representing the proportion of the mean excess returns generated by employing a strategy consistent with the risk 
premia or arbitrage opportunities presented in the literature.

\section{Data and Methodology}

\subsection{Baseline Data}

Our data consists of 3,665 individual hedge funds (1,430 active funds and 2,235 defunct funds) from the Barclay Hedge Fund DataFeeder and Barclay Graveyard Database that are reported in U.S. currency, net of all fees, and have at least 24 consecutive months of performance data between January 1, 1994 and December 31, 2008. Reported strategies contain a minimum of 10 individual hedge funds. Fama and French (1993) and Carhart (1997) factors are sourced from Kenneth French's website and Fung and Hsieh (2001) factors from David Hsieh's website. Further, data gathered using Compustat, CRSP, and SDC Global New Issues were employed to create the three anomaly factors. For an outline of the formulae used in generating the asset growth, equity financing, and earnings momentum factors, see Lawson and Schwartz (2018). Also note the transferability of precautions taken in order to mitigate survivorship bias and incubation bias where possible.

\subsection{Overview of Methodology}

Our analyses include equally-weighted portfolios constructed using the returns produced by the reporting hedge funds. Identical to our previous publication, we first develop a baseline portfolio that includes all hedge funds regardless of strategy; this is referred to as the "global portfolio". We further transform the hedge fund performance figures by computing mean returns of funds grouped into strategy-specific portfolios, rather than the global portfolio, to test arbitrage ability across distinct strategy groups ranked by performance. We re-run the regressions using historical mean excess returns of equally-weighted portfolios of hedge funds grouped by top-five best and bottom-five worst performing strategies over time.

The novel contribution of this publication to the existing work is two-fold. First, adjustments were made to the time frame under analysis in Lawson and Schwartz (2018) by bifurcating the period into the months spanning 1994 to 2000 and 2001 to 2008 rather than just continuously across 1994 to 2008 . We believe there could be significant justification for doing so. To provide theoretical context, it is not difficult to conceptualize situations where fund managers may have seen value in utilizing select anomalies during one period and other anomalies during subsequent periods. After all, investment strategies can fall in and out of favor as economic cycles evolve and it may have been operationally or economically efficient for them to do so. Agarwal and Naik (2004) show that different hedge fund strategies can call for different use of risk factors and Fung and Hsieh (2001) make note of the dynamic trading style of hedge fund investors. To make things more complex, certain anomalies may have existed during one period but been arbitraged away during subsequent periods. Therefore, our bifurcation of the time series allows for a more robust testing of how observed arbitrage may have existed dynamically through time. The factor loadings in our models would likely show increased or decreased significance and explanatory power between periods if this is the case.

The second contribution of this paper is as follows. We compare the factor loadings not just between time periods, but also address any differences in the loadings between top and bottom performing strategy portfolios. This is important because it provides a perspective on how the best and worst performers may have utilized the pricing anomalies for their betterment or failed to utilize them to their detriment. It also brings attention to the potential ignorance to the existence of pricing anomalies by lower-performing funds. The choice to utilize or not utilize certain anomalies, or ignorance to them, should be reflected in the comparison between best and worst performers. An outline of the regression models and discussion of their explanatory factors is shown below.

\subsection{The Four-Factor Model}

The four-factor model is based on the Fama and French (1993) risk factors combined with the Carhart (1997) stock-return momentum factor:

$$
R_{t}-R_{F t}=\varphi_{0}+\varphi_{1} M K T_{t}+\varphi_{2} S M B_{t}+\varphi_{3} H M L_{t}+\varphi_{4} U M D_{t}+\varepsilon_{t} \quad t=1,2, \ldots, T
$$

where $R_{t}$ is the net-of-fees, monthly, mean, equally-weighted return of the global portfolio in the month denoted by ' $\mathrm{t}$ '. The risk-free rate in the month ' $\mathrm{t}$ ' is denoted by $R_{F t}$, and $M K T_{t}, S M B_{t}, H M L_{t}$, are the Fama French (1993) market, size, and value factors, respectively. $U M D_{t}$ is the Carhart (1997) stock-return momentum factor. The error term is denoted by $\varepsilon_{t}$ and $\varphi_{\mathrm{t}}$ are the coefficients to be estimated through regression.

\subsection{The Five-Factor Model}

We regress the net-of-fees, monthly, mean equally-weighted returns of the best and worst performing portfolios on the four-factor model described in section 3.3 but we also add the earnings momentum factor ("PMN"). Chordia and Shivakumar (2006) find a strong link between earnings momentum and future stock returns and that 
PMN subsumes the effect of stock-returns momentum from Carhart (1997). We expect a positive coefficient on the earnings momentum factor if the anomaly is being successfully arbitraged but suspect a negative coefficient if the funds are knowingly or unknowingly doing the opposite of this strategy.

$$
R_{t}-R_{F t}=\varphi_{0}+\varphi_{1} M K T_{t}+\varphi_{2} S M B_{t}+\varphi_{3} H M L_{t}+\varphi_{4} U M D_{t}+\varphi_{5} P M N_{t}+\varepsilon_{t} \quad t=1,2, \ldots, T
$$

Next, we replace the earnings momentum factor with the equity financing factor ("UMO"). According to Hirshleifer and Jiang (2007), the equity financing anomaly posits the ability to generate abnormal excess returns on portfolios which are long stocks that have repurchased shares and short the stocks which have newly-issued shares. If this anomaly is being successfully arbitraged, there should be a positive factor coefficient as well. Lawson and Schwartz (2018) found significant use of this anomaly between 1994 and 2008.

$$
R_{t}-R_{F t}=\varphi_{0}+\varphi_{1} M K T_{t}+\varphi_{2} S M B_{t}+\varphi_{3} H M L_{t}+\varphi_{4} U M D_{t}+\varphi_{5} U M O_{t}+\varepsilon_{t} \quad t=1,2, \ldots, T
$$

Lastly, we replace the equity financing factor with the asset-growth factor ("AGF"). Based on Cooper, Gulen, and Schill (2007), abnormal profits can be realized by investing in portfolios of common stocks which are created by going long companies with the lowest decile asset growth and shorting those with the highest decile asset growth. Arbitraging on the AGF anomaly should result in a positive factor coefficient. Lawson and Schwartz (2018) found significant use of this anomaly as well.

$$
R_{t}-R_{F t}=\varphi_{0}+\varphi_{1} M K T_{t}+\varphi_{2} S M B_{t}+\varphi_{3} H M L_{t}+\varphi_{4} U M D_{t}+\varphi_{5} A G F_{t}+\varepsilon_{t} \quad t=1,2, \ldots, T
$$

\subsection{Seven-Factor Model}

The seven-factor model is a comprehensive model with all of the variables previously mentioned: the market ("MKT"), size ("SMB"), and value ("HML") risk factors, the stock-return momentum factor ("UMD"), and the earnings momentum ("PMN"), equity financing ("UMO"), and asset growth ("AGF") factors. The full model is:

$$
\begin{gathered}
R_{t}-R_{F t}=\varphi_{0}+\varphi_{1} M K T_{t}+\varphi_{2} S M B_{t}+\varphi_{3} H M L_{t}+\varphi_{4} U M D_{t}+\varphi_{5} P M N_{t}+\varphi_{6} U M O_{t}+\varphi_{7} A G F_{t}+\varepsilon_{t} \\
t=1,2, \ldots, T
\end{gathered}
$$

\subsection{Eight-Factor Model}

The eight-factor model is designed to account for the potential non-linearity of hedge fund returns. To do so, it replaces the Fama and French (1993) and Carhart (1997) factors with the Fung and Hsieh (2001) Primitive Trend-Following Strategy factors which represent bond ("PTFSBD"), currency ("PTFSFX"), commodity ("PTFSCOM"), short-term interest rate ("PTFSIR"), and stock index ("PTFSSTK") lookback straddles. Additionally, the model incorporates the aforementioned earnings momentum ("PMN"), equity financing ("UMO"), and asset growth ("AGF") factors sequentially and then all at once. The full model specification is:

$$
\begin{gathered}
R_{t}-R_{F t}=\varphi_{0}+\varphi_{1} \text { PTFSBD }_{t}+\varphi_{2} \text { PTFSFX }_{t}+\varphi_{3} \text { PTFSCOM }_{t}+ \\
\varphi_{4} \text { PTFSIR }_{t}+\varphi_{5} \text { PTFSSTK }_{t}+\varphi_{6} \text { PMN }_{t}+\varphi_{7} \text { UMO }_{t}+\varphi_{8} \text { AGF }_{t}+\varepsilon_{t} \quad t=1,2, \ldots, T
\end{gathered}
$$

\section{Results}

\subsection{Analyzing the Top 5 Performing Strategies Using Linear-Factor Models (1994 to 2000 and 2001 to 2008)}

Table 1 shows the regression results for the monthly, equally-weighted, net-of-fees, excess returns generated by the hedge funds ranking in the top five best performing strategy groups with at least ten reported funds between the time periods 1994 to 2000 and 2001 to 2008 .

For the period 1994 to 2000, the market and size risk premiums seemed to play a significant role in explaining the captured variation in excess returns for the top five performing strategy groups. The value premium had inconsistent results across models, but when significant, did add constructively by improving incremental excess returns. Unfortunately, both the returns momentum factor and the earnings momentum factor were insignificant across all models for the 1994 to 2000 period. The various regressions suggest that top performing hedge funds by strategy had tended to exert emphasis on the asset growth and equity financing anomalies to generate excess returns, in addition to the traditional market and size risk premiums. Ultimately, hedge funds did generate positive alpha significant at the $1 \%$ level, just to varying degrees dependent upon the model employed.

For the period 2001 to 2008 , the market risk premium was again positive across all regressions. Interestingly, the size factor lost significance entirely and Carhart's returns momentum factor gained $1 \%$ significance consistently across all model outputs. This suggests some sort of time-varying nature to arbitrage techniques across top performing hedge funds. As with the earlier time period, hedge funds seemed to successfully arbitrage on the asset growth anomaly to their benefit, and had produced alpha at the $1 \%$ level. This performance could have been even better if only they had taken a long position in firms exhibiting share buybacks and shorting firms 
exercising new issuance, which they did not, as evidenced by the negative coefficient on the equity financing factor for this period.

Table 1. Time series regression of Top 5 performing strategies with 10 or more funds between 1994-2000 and 2001 to 2008

\begin{tabular}{|c|c|c|c|c|c|c|c|c|}
\hline & \multicolumn{4}{|c|}{1994 to 2000} & \multicolumn{4}{|c|}{2001 to 2008} \\
\hline & (1) & (2) & (3) & (4) & (5) & (6) & (7) & (8) \\
\hline Observations & 6565 & 6565 & 6565 & 6565 & 18346 & 18346 & 18346 & 18346 \\
\hline R-squared & 0.03 & 0.03 & 0.03 & 0.04 & 0.02 & 0.02 & 0.02 & 0.03 \\
\hline
\end{tabular}

\subsection{Analyzing the Bottom 5 Performing Strategies Using Linear-Factor Models (1994 to 2000 and 2001 to 2008)}

Table 2 shows the regression results for the monthly, equally-weighted, net-of-fees, excess returns generated by the hedge funds ranking in the bottom five worst performing strategy groups with at least ten reported funds between the time periods 1994 to 2000 and 2001 to 2008 .

For the period 1994 to 2000 , the traditional market, size, and value premiums loaded positively and significantly at the $1 \%$ level across all model varieties. This implies that the average hedge fund, which ultimately falls in the worst performing strategy groups, tended to have made use of the size and value characteristics in their investment actions. Asset growth arbitrage was also present at the $1 \%$ level, consistent with what was seen for the top performing funds. Carhart's returns momentum factor and the earnings momentum factor played no role in the generation of excess returns according to our estimation. In the seven-factor model the equity financing factor was significant at the $10 \%$ level but showed a detractionary effect on excess returns due to the nature of manager investment decisions. Such decisions proxied the act of going short repurchase firms and long new issue firms, when existing empirical work recommends the opposite. Positive alpha was not present in any model.

For the period 2001 to 2008, the strong loadings on the market, size, and asset growth factors at the $1 \%$ level had once again improved hedge fund performance. Interestingly, the value factor lost all significance during the time period while Carhart's momentum factor gained significance ranging from the $1 \%$ to $5 \%$ level. This is the same time-varying arbitrage phenomenon seen in the performance of the top five performing strategies. Furthermore, earnings momentum seemed to pick up significance as well, unlike the results seen in the top performers where earnings momentum appeared to play no role in generating excess returns at all. As was the case for the prior holding period, no positive alpha had been generated by the bottom performing funds.

As an additional point of discussion, it should be noted that model performance had improved quite meaningfully when examining the lower performing hedge funds. In fact, for the 2001 to 2008 period, R-squared values had reached $20 \%$ suggesting our models explained just shy of a quarter of all observed variation in average excess returns. This was a substantial improvement over the R-squared value from the model analyzing the top performing funds.

Table 2. Time series regression of bottom 5 performing strategies with 10 or more funds between 1994-2000 and 2001 to 2008

\begin{tabular}{|c|c|c|c|c|c|c|c|c|}
\hline & \multicolumn{4}{|c|}{1994 to 2000} & \multicolumn{4}{|c|}{2001 to 2008} \\
\hline & (1) & (2) & (3) & (4) & $(5)$ & (6) & (7) & $(8)$ \\
\hline Observations & 15347 & 15347 & 15347 & 15347 & 62355 & 62355 & 62355 & 62355 \\
\hline R-squared & 0.1 & 0.1 & 0.1 & 0.1 & 0.2 & 0.21 & 0.2 & 0.21 \\
\hline
\end{tabular}

\section{Conclusions}

Our results indicate that the top and bottom performing hedge fund strategies made consistent use of the heavily-vetted market and value risk premiums and market and size risk premiums, respectively, in order to produce excess returns. Asset growth arbitrage also seemed to persist over both analysis periods for top and bottom performers indicating that funds were rewarded for investing long firms that had historically operated with low asset growth and short firms with rather high asset growth. Use of the equity financing anomaly proved beneficial and detrimental for top performers as they had chosen to take the profitable position during the first measurement period but ultimately loaded negatively on the factor for the latter period. A switch in the 
significance of the size and momentum factors was also found when analyzing the top performers, providing further evidence of a potentially intentional or unintentional alteration of investment strategy involving size and returns momentum. A likewise switch between the value and returns momentum factors existed between the time periods among the bottom performers. This breeds attention to the notion of hedge fund strategies staying consistent in their philosophy at the broad level, but evolving dynamically through time at the trading level.

Ultimately, we had expected more robust use of the risk factors and documented market pricing anomalies to generate profit from both top and bottom performing sub-samples, but the opposite seemed to be the case. The bottom performing hedge fund strategies consistently loaded positive on the market, size, and asset growth factors and the top performers loaded positively on the market, value, and asset growth factors. Neither group consistently made effective use of the equity financing or earnings momentum factors.

Also interesting, the R-squared on the models applied to low performing strategies was remarkably greater than the R-squared on the models applied to the top performers. While a twenty percent explanation of variation in excess returns is relatively good for a set of linear models applied to hedge funds, why isn't the explanatory power even greater, especially given the fact that the Fama and French (1993) and Carhart (1997) models tend to wield R-squared values exceeding $90 \%$ ? We have a few hypotheses.

First, the performance data is self-reported by hedge fund managers. This could be corrected by alternatively scrubbing 13-F SEC filings and estimating performance, so long as the universe of hedge funds is large enough and holdings periods can be accurately deduced by the filings. This may be challenging and accurate at best and challenging and inaccurate at worst.

Second, existing literature documents the drop in explanatory power of mainstream asset pricing models when tested internationally, especially in less-than-efficient capital markets. For example, Fama, French, and other authors have noted varying levels of factor explanatory power in explaining cross-sectional returns of common stocks across various non-US markets. Hedge funds likely bear significant international exposure, so perhaps our model is not as robust as it could be simply because traditional multi-factor models don't work as well abroad. The international components of other style-based regressions, like that of Sharpe (1992), use MSCI international market indices to proxy developed and emerging market exposures. We did not employ such style-based models of performance attribution and likely failed to capture excess returns generated from international holdings.

Third, and most notably, hedge funds can certainly act as multi-asset investment managers. They do not have to invest solely in common stocks. They can invest in corporate bonds, municipal bonds, government and agency securities, securitized assets, commodities, real estate, currencies, and preferred shares, among other things. The PTFS straddle option factors take a step towards accounting for some of this, but we are not sure it does so comprehensively. For example, it is well established that pricing models for common stocks are specified differently than models for bonds. Bonds are priced as a function of the real risk free rate, expected inflation, default risk premium, and term premium. Stocks are priced as a function of the real risk free rate, expected inflation, and a market risk premium with the potential to also include value and size premiums. Other factors such as those used in our paper are anomalies, not risk factors. Nonetheless, we could consider adding an additional risk factor capturing changes in credit risk. Agarwal and Naik (2004) include the variation in default spreads, as measured by the difference in the yield on BAA-rated corporates and ten-year U.S. Treasury bonds, for their study. This could provide a step towards specifying a model that can capture variation in excess fund returns attributable to holding fixed income securities.

\section{References}

Agarwal, V., \& Naik, N. (2004). Risks and portfolio decisions involving hedge funds. Review of Financial Studies, 17, 63-98. https://doi.org/10.1093/rfs/hhg044

Breeden, D. T. (1979). An intertemporal asset pricing model with stochastic consumption and investment $\begin{array}{lllll}\text { opportunities. Journal of } & \text { Financial }\end{array}$ https://doi.org/10.1016/0304-405X(79)90016-3

Breeden, D. T., Gibbons, M. R., \& Litzenberger, R. H. (1989). Empirical test of the consumption-oriented CAPM. The Journal of Finance, 44(2), 231-262. https://doi.org/10.1111/j.1540-6261.1989.tb05056.x

Carhart, M. (1997). On persistence in mutual fund performance. Journal of Finance, 52, 57-82. https://doi.org/10.1111/j.1540-6261.1997.tb03808.x

Chordia, T., \& Shivakumar, L. (2006). Earnings momentum and price momentum. Journal of Financial Economics, 80, 627-656. https://doi.org/10.1016/j.jfineco.2005.05.005 
Cooper, M., Gulen, H., \& Schill, M. (2007). Asset growth and the cross-section of stock returns. Journal of Finance, forthcoming. https://doi.org/10.2139/ssrn.760967

Fama, E., \& French, K. (1993). Common risk factors in the returns on stock and bonds. Journal of Financial Economics, 33, 3-56. https://doi.org/10.1016/0304-405X(93)90023-5

Fung, W., \& Hsieh, D. A. (2001). The risk in hedge fund strategies: Theory and evidence from trend followers. The Review of Financial Studies, 14(2), 313-341. https://doi.org/10.1093/rfs/14.2.313

Hirshleifer, D., \& Jiang, D. (2007). Commonality in misvaluation, equity financing, and the cross section of stock returns.

Jegadeesh, N., \& Titman, S. (1993). Returns to buying winners and selling losers: Implications for stock market efficiency. The Journal of Finance, 48(1), 65-91. https://doi.org/10.1111/j.1540-6261.1993.tb04702.x

Lawson, D., \& Schwart, R. (2018). Do hedge funds arbitrage on asset growth, earnings momentum and equity financing anomalies. International Journal of Economics and Finance, 10(9), 38-45. https://doi.org/10.5539/ijef.v10n9p38

Litner, J. (1965a). The valuation of risk assets and the selection of risky investments in stock portfolios and capital budgets. The Review of Economics and Statistics, 47, 13-37. https://doi.org/10.2307/1924119

Litner, J. (1965b). Securities prices, risk, and maximal gains from diversification. The Journal of Finance, 20(4), 587-615. https://doi.org/10.1111/j.1540-6261.1965.tb02930.x

Markowitz, H. (1952). Portfolio selection. The Journal of Finance, 7(1), 77-91. https://doi.org/10.1111/j.1540-6261.1952.tb01525.x

Merton, R. C. (1973). An intertemporal capital asset pricing model. Econometrica, 41(5), 867-887. https://doi.org/10.2307/1913811

Mitchell, M., \& Pulvino, T. (2001). Characteristics of risk and risk arbitrage. Journal of Finance, 56, 2135-2175. https://doi.org/10.1111/0022-1082.00401

Mossin, J. (1966). Equilibrium in a capital asset market. Econometrica: Journal of the Econometric Society, 768-783. https://doi.org/10.2307/1910098

Reinganum, M. R. (1981). Misspecification of capital asset pricing: Empirical anomalies based on earnings' yield and market values. Journal of Financial Economics, 9(1), 19-46. https://doi.org/10.1016/0304-405X(81)90019-2

Ross, S. (1976). The arbitrage theory of capital asset pricing. Journal of Economic Theory, 13(3), 341-360. https://doi.org/10.1016/0022-0531(76)90046-6

Sharpe, W. F. (1964). Capital asset prices: A theory of market equilibrium under conditions of risk. The Journal of Finance, 19(3), 425-442. https://doi.org/10.1111/j.1540-6261.1964.tb02865.x

Sharpe, W. F. (1992). Management style and performance measurement. The Journal of Portfolio Management, 18(2), 7-19. https://doi.org/10.3905/jpm.1992.409394

Treynor, J. L. (1961). Market value, time, and risk. Unpublished Manuscript. "Rough Draft" dated 8/8/61, \#95-2009. https://doi.org/10.2139/ssrn.2600356

Treynor, J. L. (1962). Toward a theory of market value of risky assets. Unpublished manuscript, 6, 831-868.

\section{Copyrights}

Copyright for this article is retained by the author(s), with first publication rights granted to the journal.

This is an open-access article distributed under the terms and conditions of the Creative Commons Attribution license (http://creativecommons.org/licenses/by/4.0/). 